\title{
The effect of melody and technique on the singing voice accuracy of trained singers
}

\author{
PAULINE LARROUY-MAESTRI ${ }^{1}$, DAVID MAGIS ${ }^{2} \&$ DOMINIQUE MORSOMME $^{1}$ \\ ${ }^{1}$ Logopédie de la Voix, Department of Psychology: Cognition and Behaviour, University of Liège, Belgium, and \\ ${ }^{2}$ Department of Education, University of Liège, Belgium
}

\begin{abstract}
A previous study highlighted the effect of vocal technique on the singing voice accuracy of trained singers. The intervals' precision between the notes of the tune was altered when the singers used Western operatic singing technique. In order better to understand these results, we have recorded two different melodies sung with two different vocal techniques. A large panel of trained singers $(n=50)$ participated in the study. The analytical method described in the reference paper has been applied. The results confirm the effect of vocal technique on the vocal accuracy of trained singers. In addition, these results provide an answer about the melodic effect and guide future work on the perception process of operatic voices.
\end{abstract}

Key words: Acoustic analyses, operatic technique, singing, sung performance, vocal accuracy

\section{Introduction}

In a melodic context, the vocal accuracy is observed through the fundamental frequency variations in the tune and has been shown as an important parameter to assess the quality of a sung performance (1). The most common criterion used in objective assessment of a vocal performance is the pitch interval deviation, estimated by measuring the difference between the size of intervals performed and the standard size based on the musical notation (2-6).

In a recent study (7), the authors have compared the sung performances of 63 untrained singers and 14 trained singers of the popular song 'Happy Birthday'. As expected, the professional singers were more accurate than the untrained ones. However, when a Western operatic singing technique was used by the trained singers, the size of the intervals was particularly deviated from the musical notation. The effect of the technique observed in this study could be discussed regarding the small number of participants, but also regarding the interpretation effect of the trained singers. Indeed, the simple and familiar melody 'Happy Birthday' is not part of the classical vocal repertory. An over-interpretation may be the cause of the inaccuracy of the trained singers, who would exaggerate the melodic contour of the song and add ornaments. From roughly the first decade of the 19th century to the middle 20th century, the romantic era music was characterized by increased attention to the expressivity of the melodic line (e.g. (8)). Within the stylistic characteristics of this musical period, one can note complex modulations, tonal ambiguity with harmonic tensions and surprising cadences, warm and expressive melodies, as well as ornaments with appoggiatura, trill, turn, mordent, or arpeggio (e.g. (9)). The transfer of these stylistic characteristics on a simple popular song would consequently alter the intervals' precision and thus this vocal accuracy criterion. Indeed, the singers would be less strict as far as the precision of intervals is concerned in order to make it sound like a Western romantic song.

The present study aimed (a) to confirm the effect of singing technique observed in the previous study and (b) to observe if the choice of the melody has an effect on the vocal accuracy. For (a), a large group of trained singers was instructed to perform the Happy Birthday song with two different vocal techniques ('naturally' and with a Western operatic singing technique). For (b), the same participants 
were asked to select and to sing a romantic melody of their musical repertory, with two contrasting singing techniques.

\section{Method}

\section{Participants}

A total of 50 professional or semi-professional singers (38 women, 12 men), from 19 to 66 years old ( $M=36.94$ years), participated in the study. They all had an education in classical music and regularly engaged in classical solo vocal performances. They began singing lessons between 6 and 49 years of age $(M=20.18$ years), and they had between 5 and 51 years of singing experience ( $M=19.86$ years). They reported to practise their vocal instrument 13.68 hours/week on average.

\section{Material and procedure}

The sound recordings were made using a head-worn microphone Sennheiser HS2 (Wedemark, Germany) positioned at a constant distance of $2 \mathrm{~cm}$ from the right corner of the mouth as well as a Marantz Professional Solid State Recorder PMD67 (Kanagawa, Japan). All these sung performances have been listed in a database, which can be viewed following the link: http://sldr.org/sldr000792/en.

As in the previous study, participants were first asked to produce two vocal glissandi to warm up the vocal organs (10) and to encourage a lack of inhibition in front of the experimenter and the recording equipment. Then, they individually performed, a cappella, two different melodies (the popular song 'Happy Birthday' and a romantic melody of their choice) with two different techniques (singing without any particular technique and with a Western operatic singing technique). Concerning the chosen melody, the participants had to choose a romantic melody of their musical repertory (i.e. Lieder of Schubert, Schumann). Except for the chosen melody, no particular starting note was given in order to let the participant perform in his/her comfortable range.

The four vocal performances were recorded following a precise order: the French version of the popular birthday melody 'naturally' (i.e. whilst imagining a festive and friendly context) (birthday), the chosen melody 'naturally' (romantic), the chosen melody with a Western operatic singing technique 'like on stage' (ROMANTIC), and finally the birthday song with a Western operatic singing technique (BIRTHDAY).

\section{Acoustic analysis}

For the four performances of each participant (birthday, romantic, ROMANTIC, BIRTHDAY), the pitch interval deviation was computed following the analytical procedure of Larrouy-Maestri and Morsomme (7). In order to observe the respect of the tonality of the tune, we have chosen to compute the number of tonality modulations. Indeed, the tonal centre was not always clear because of the length of the musical excerpts. Also, the number of tonality modulations appeared as a better criterion to observe the respect of the tonality of the tune than the tonal centre deviation used in the reference paper (7). Note that, in order to compare the chosen melodies and the popular song (containing 21 notes analysed), the excerpts selected contained from 14 to 28 notes $(M=20.76$, $E S=3.61)$. One tonality modulation corresponds to an interval error of more than 100 cents (one semitone), which is not compensated by an error in the other direction (for details, see Larrouy-Maestri et al. (11)). All the acoustic analyses were run on a Macintosh (Mac OS X, Version 10.6.8).

\section{Statistical analysis}

The pitch interval deviation and the number of tonality modulations were modelled separately by means of a multiple regression model, with the type of melody and the technique as covariates. An interaction effect between the melody and the technique was also included in the initial model. The model was then simplified by removing all not statistically significant tests, using the likelihood ratio test for nested models (12). The significance level was fixed to $5 \%$. The simplest model was retained and discussed for further investigation of statistically significant trends.

\section{Results}

For each of the four conditions ( 2 melodies $\times 2$ techniques), the pitch interval deviation and the number of tonality modulations criteria for the 50 singers are represented in Table I.

Table II displays a summary of the $P$ values for both main effects (melody and technique) to each response variable modelling. Note that the interaction between melody and technique variables was

Table I. Descriptive analyses of the pitch interval deviation (in cents) and the number of tonality modulations for the four sung performances.

\begin{tabular}{llrrrrr}
\hline & & \multicolumn{2}{c}{ Popular song } & & \multicolumn{2}{c}{ Chosen melody } \\
\cline { 3 - 4 } \cline { 6 - 7 } Variables & Stat. & birthday & BIRTHDAY & & romantic & ROMANTIC \\
\hline \multirow{2}{*}{ Intervals } & Mean & 28.788 & 37.606 & & 34.307 & 42.568 \\
& SE & 3.364 & 4.136 & & 3.093 & 2.769 \\
\multirow{2}{*}{ Modulations } & Mean & 0.240 & 0.360 & & 0.500 & 0.540 \\
& SE & 0.089 & 0.103 & & 0.109 & 0.126 \\
\hline
\end{tabular}


Table II. $P$ values of the effects of the melody and the technique on the variables.

\begin{tabular}{lcc}
\hline Variables & Melody & Technique \\
\hline Intervals & 0.118 & 0.012 \\
Modulations & 0.040 & 0.453 \\
\hline
\end{tabular}

never statistically significant and is therefore skipped from this table.

The effect of the technique is significant for the pitch interval deviation criterion: the Western operatic singing technique yields an increase of the pitch interval deviation $(P=0.012)$. However, this vocal technique does not disturb the tonal centre of the tune $(P=0.453)$. The effect of the melody is statistically significant only for the number of tonality modulations $(P=0.040)$. It can be observed from the final model that singing the chosen melody leads to more tonality modulations than in the popular song. Moreover, as can be seen in Table II, no effect of melody occurred for the pitch interval deviation criterion $(P=0.118)$.

\section{Discussion and conclusion}

This study confirms the findings of Larrouy-Maestri and Morsomme (7) concerning the effect of technique on the singing voice accuracy (Table II). Indeed, among the 50 trained singers, the use of Western operatic singing technique leads to a high pitch interval deviation in the sung performance. We also found that the respect of the tonal centre (number of tonality modulations) did not vary according to the singing technique. However, this criterion was sensible to the melodic effect. The number of tonality modulations was significantly more important for the chosen melody than for the popular song. This result is not surprising regarding the size of the excerpts selected. For experimental reasons, we wished to observe two different melodies containing an equivalent number of notes: one popular song (21 notes) and one from their musical repertory. The participants were thus asked to choose excerpts in accordance with the musical notation (respect of phrases and articulation) but also with an equivalent length as the popular song. This selection allowed comparing the two melodies, but the harmonic component of the romantic melody was less clear as it was not performed in its complete version. The trained singers showed more difficulties to respect the tonal centre in the excerpt from the romantic melody than in the full popular song.

The fact that the singers were particularly out of tune (high pitch interval deviation) when they sang with a Western operatic singing technique was already surprising in the previous study. We pointed out that an over-interpretation could explain the inaccuracy of the trained singers by the exaggeration of the melodic contour of the song and the addition of ornaments. Thanks to the analysis of two different melodies (popular song and romantic melody chosen by each participant), we observed no effect of the melody on the singing voice accuracy (Table II). Indeed, for both melodies, the singers were more out of tune when they used the Western operatic singing technique than when singing 'naturally'. The hypothesis of an over-interpretation of the popular song, which is not adapted to the daily practice of the trained singers, has not been confirmed. For future researches on trained singers, the choice of the melody would not have consequences on the vocal accuracy.

Finally, regarding the profile of the trained singers (low interval precision when the Western operatic singing technique is employed), the accuracy of the pitch intervals is perhaps less important when this vocal technique is employed than for untrained singers or trained singers singing 'naturally'. This criterion is commonly used in experimental researches (2-6) and explains a large part of music experts' evaluation in a context of untrained singers (11). However, listeners could be willing to accept pitch alterations if it adds or is completed by other components. This question about pitch importance could be a relevant subject for further investigation, for example by the confrontation of the objective evaluation of the sung performances of this study with music experts' rating.

\section{Acknowledgements}

The authors thank the 'Centre Henri Pousseur' of Liège and Guillaume Videlier for the technical support of acoustic analyses. We also thank the singers who took part in this experiment and Marion Nowak for her help with the data collection.

Declaration of interest: This research has received no specific grant from any funding agency in the public, commercial, or not-for-profit sectors. The authors report no conflicts of interest.

\section{References}

1. Watts C, Barnes-Burroughs K, Andrianopoulos $M$, Carr M. Potential factors related to untrained singing talent: a survey of singing pedagogues. J Voice. 2003;17: 298-307.

2. Berkowska $M$, Dalla Bella S. Reducing linguistic information enhances singing proficiency in occasional singers. Ann NY Acad Sci. 2009;1169:108-11.

3. Dalla Bella S, Berkowska M. Singing proficiency in the majority. Ann NY Acad Sci. 2009;1169:99-107. 
4. Dalla Bella S, Giguère J-F, Peretz I. Singing proficiency in the general population. J Acoust Soc Am. 2007;121:1182-9.

5. Pfordresher $\mathrm{PQ}$, Brown S. Enhanced production and perception of musical pitch in tone language speakers. Atten Percept Psychophys. 2009;71:1385-98.

6. Pfordresher PQ, Brown S, Meier KM, Belyk M, Liotti M. Imprecise singing is widespread. J Acoust Soc Am. 2010; 128:2182-90.

7. Larrouy-Maestri P, Morsomme D. Criteria and tools for objectively analysing the vocal accuracy of a popular song. Logoped Phoniatr Vocol. 2014;39:11-8.

8. Samson J. Romanticism. In: Sadie S, Tyrrell J, editors. The New Grove Dictionary of Music and Musicians. 2nd ed. London: Macmillan Publishers; 2001. Vol. 21, pp. 596-603.

9. Hanning BR. Concise history of Western music. 4th ed. New York: Norton \& Company. 2010. pp. 1-585.

10. Amir O, Amir N, Michaeli O. Evaluating the influence of warmup on singing voice quality using acoustic measures. J Voice. 2005; 19:252-60.

11. Larrouy-Maestri $P$, Lévêque $Y$, Schön $D$, Giovanni A, Morsomme D. The evaluation of singing voice accuracy: a comparison between subjective and objective methods. J Voice. 2013;27:259.e1-259.e5.

12. Agresti A. An introduction to categorical data analysis. New York: Springer; 1996. pp. 88-89. 